\title{
STUDIES ON SEED GERMINATION OF PUMMELO (CITRUS GRANDIS L. OSBECK)
}

\author{
R. R. KHOPKAR, D. NAGAHARSHITHA, P. C. HALDAVANEKAR \& Y. R. PARULEKAR \\ Department of Horticulture, College of Agriculture, Dapoli, \\ Dr. Balasaheb Sawant Konkan krishi Vidyapeeth, Maharashtra, India
}

\begin{abstract}
Pummelo seeds are classified as recalcitrant seeds, do not tolerate the low moisture level, low temperature storage or strong light. To carry out successful breeding programmed and also for genetical as well as rootstock studies, it is essential to have a high percentage of seed germination and uniform size of the seedlings. The present study was carried out to investigate the effect of GA3 solution and storage period on rate of seed germination and on growth of pummelo seedlings. For this aim; the trial was conducted in FRBD, with two factors viz., three levels of storage period and seven pre-sowing seed treatments. Thus, there were 21 treatment combinations and were 8 replicated thrice. The storage period was S1- fresh seeds, S2-15 days stored seeds at ambient temperature, S3- 30 days stored seeds at ambient temperature. Different pre-sowing seed treatments were T1- control (i.e. No seed treatment), T2- water soaking for 24 hrs, T3- scalding at 50 C for 24 hrs, T4- soaking of seeds in 50 ppm GA3 solution for 24 hours, T5- soaking of seeds in 100 ppm GA3 solution for 24 hours, T6- soaking of seeds in 150 ppm GA3 solution for 24 hours, T7- soaking of seeds in 200 ppm GA3 solution for 24 hours. Observations on leaf area, 14 root volume; AGR (absolute growth rate) and RGR (relative growth rate) were recorded at 6 months age. Among, different physiological parameters studied, storage period had a significant effect on most of the characters viz; leaf area, root volume, AGR and RGR. From the result obtained and analyzed, during the present investigation, it could be concluded that, most of the pre-sowing seed treatments and their interaction effect, like freshly harvested seeds soaked with GA3 at 50 ppm for 24 hrs, followed by scalding at 50 C for 24 hrs treated pummelo seeds had shown better results, on percent germination and most of the growth parameters of pummelo seedlings than control.
\end{abstract}

KEYWORDS: Pummelo, Absolute Growth Rate, Gibberellic Acid \& Relative Growth Rate

Received: Aug 15, 2017; Accepted: Sep 05, 2017; Published: Sep 20, 2017; Paper Id.: IJASROCT201731

\section{INTRODUCTION}

Citrus is one of the most important fruits and extensively grown in tropical and sub-tropical parts of the world. In India, citrus is the third most important fruit crop after banana and mango. In India, mandarins, sweet oranges, limes, lemons, pummelo and grapefruit are important citrus fruits grown commercially. The pummelo is a crisp citrus fruit, which belongs to family Rutaceae and native to Southeast Asia. Pummelo, (Citrus grandis L. Osbeck.) mainly knew, as the principal ancestor of the grapefruit. Eventhough, it is an underutilized fruit crop, it has a potential for the commercialization in warm and humid climate.

In large parts of South East Asia, it is a popular dessert, often eaten raw sprinkled with or dipped in the salt mixture. It is also eaten in salads or together with yogurt, and sometimes pickled. Having excellent keeping quality, due to the presence of very thick rind, pummelos are ideal for long transportation, either domestically or export. Pummelo fruit is usually pale green to yellow when ripe, with sweet white (more rarely, pink or red) flesh 
and very thick albedo (rind pith). It is the largest citrus fruit, 15-25 cm in diameter and usually weighing 1-2 kilograms. Pummelo trees are spiny, spreading 4-14 $\mathrm{m}$ in height. Pummelo is the biggest citrus fruit. The fruit is hesperidium and ranges from nearly round to oblate or pear shaped. The rind is thick, leathery peel or exocarp containing many oil glands, known as the 'flavedo'. Pummelo seeds are large, plump, pale yellowish white, flattened and angular, they are usually monoembryonic. The pummelo tree prefers hot and humid tropical climate, at low altitudes close to the sea. It cannot grow well in high altitude (above $400 \mathrm{~m}$ ), or in cooler climates (Narong et al., 2005). Pummelo tolerates a wide range of soils, from coarse sand to heavy clay, but deep, medium-textured, fertile soil free from injurious salts is preferred.

Pummelo is usually grafted onto other citrus rootstocks, but can be grown from seed, provided the seeds are not allowed to dry out before planting. Only, the best varieties are vegetatively propagated traditionally, by air-layering, but more modernly by budding onto rootstocks of pummelo, 'King' or 'Cleopatra' mandarin, rough lemon, or Rangpur lime. In experimental work, in the United States, the "T", or shield-budding, method has been found most satisfactory.

The rate and extent of seed germination in citrus, varies according to species, varieties and season. The percentage and rate of seed germination are very less in citrus species. In Malta and Hill Lemon (Citrus Limon) the germination percentage was only 23.2 and 46.5 per cent, respectively, when sown in January (Srivastava and Singh 1965). Thus, a lot of expenditure and time is spent for maintenance of rootstock seedlings.

It is highly essential to accelerate the seed germination and growth rate of citrus seedling by treating with growth substances to attain biddable size earlier, such forcing of growth may ultimately reduce the cost in raising budded citrus plants. Several workers reported that gibberellic acid increases either germination rates, for instance, in sweet orange (Burns and Coggins 1969), Cleopatra mandarin and sour orange (Rawash et al. 1980). Citrus seeds lose viability, if stored for long periods. The usual practice is therefore to immediately sow them after extraction. Investigations of the causes of the rapid loss of viability of citrus seeds have shown that the seeds cannot tolerate drying below critical moisture content and require a relatively high humidity storage atmosphere.

Pummelo seeds are classified as recalcitrant seeds do not tolerate the low moisture level, low temperature storage or strong light. The germination of fresh citrus seeds is not rapid and that of dried seeds, even slower (Khan, Waseem, Ali Soetisna, M.W. King and E.H. Roberts 1985). To carry out successful breeding programmed and also for genetical as well as rootstock studies, it is essential to have a high percentage of seed germination and uniform size of the seedlings.

In view of the less percentage of germination and poor seedling growth and the response of seed storage, it was felt necessary to study seed germination of pummelo.

\section{MATERIALS AND METHODS}

An investigation "Study of seed germination of Pummelo (Citrus grandis L. Osbeck)", during the period AprilDecember 2012 was carried out at the department of Horticulture, College of Agriculture Dapoli, and Dist. Ratnagiri. Dapoli is situated on the west coast of Maharashtra, at an altitude of 280 meters above mean sea level. It is located in $17 \mathrm{o}$ $45 \&$ quot; North, longitude and 73 o 12" east longitude. The climate is warm and humid almost throughout the year, with less fluctuation in the daily temperatures. The mean annual rainfall is $3000 \mathrm{~mm}$; which is normally distributed from June to September. The soils of this region are lateritic, porous and acidic in reaction with $\mathrm{p} \mathrm{H}$ range of 5.6 to 6.0. The field experiment was conducted at the Fruit crop, nursery, Department of Horticulture, College of Agriculture, Dr. Balasaheb Sawant Konkan Krishi Vidyapeeth, Dapoli. There were two factors viz., three levels of storage period and seven pre- 
sowing seed treatments thus, 21 treatment combinations and were replicated thrice. The storage period was $S_{1}$ - fresh seeds, $\mathrm{S}_{2}-15$ days stored seeds at ambient temperature, $\mathrm{S}_{3-} 30$ days stored seeds at ambient temperature. Different pre-sowing seed treatments were $\mathrm{T}_{1^{-}}$control (i.e. No seed treatment), $\mathrm{T}_{2^{-}}$water soaking for $24 \mathrm{hrs}, \mathrm{T}_{3^{-}}$scalding at $50^{\circ} \mathrm{C}$ for $24 \mathrm{hrs}$, $\mathrm{T}_{4^{-}}$ soaking of seeds in $50 \mathrm{ppm} \mathrm{GA}$ solution for 24 hours, $\mathrm{T}_{5^{-}}$soaking of seeds in $100 \mathrm{ppm} \mathrm{GA}_{3}$ solution for 24 hours, $\mathrm{T}_{6^{-}}$ soaking of seeds in $150 \mathrm{ppm} \mathrm{GA}$ solution for 24 hours, $\mathrm{T}_{7}$ - soaking of seeds in $200 \mathrm{ppm} \mathrm{GA}_{3}$ solution for 24 hours. Seeds were extracted from uniform sized, fully matured fruits from healthy pummelo trees. The seeds were immediately sown after extraction from fruits for fresh seed sowing by giving the treatments as detailed above. Gather seeds were dried in partial shade for a day and stored at room temperature for 15 days and 30 days of sowing for the next sowing as per treatment details. There were fifty numbers of pummelo seedlings / treatment combination in one replication. Management of pummelo seedlings was carried out as per the recommended package of practices. The solutions of $\mathrm{GA}_{3}$ as per required concentrations were prepared and pre-sowing seed treatment was given as per treatment details. In control, seeds were sown without any pre-sowing seed treatment. Observations on various parameters viz, leaf area, no. of leaves, length of tap root, root volume, AGR (Absolute growth rate of plant height; cm/day), RGR (Relative growth rate in plant height; $\mathrm{cm} / \mathrm{cm} /$ day) were recorded from randomly selected five pummelo seedlings in each treatment combinations. The data obtained in the present investigation was statistically analyzed by the method, suggested by Panse and Sukhatme (1985).

\section{RESULTS AND DISCUSSIONS}

The data pertaining leaf area $\left(\mathrm{cm}^{2}\right)$ per plant as influenced by $\mathrm{GA}_{3}$ are presented in Table 1 . At 6 months age, leaf area was significantly varied from $340.64 \mathrm{~cm}^{2}$ to $546.83 \mathrm{~cm}^{2}$ among all storage period treatments. Significantly, the highest $\left(546.83 \mathrm{~cm}^{2}\right)$ leaf area was observed in $S_{1}$ treatment, which was significantly superior, over all storage period treatments. Seed storage, treatment showing leaf areas in descending order is as follows $S_{1}>S_{2}>S_{3}$. Regarding the effect of presowing seed treatment the highest $\left(518.78 \mathrm{~cm}^{2}\right)$ leaf area was observed in $\mathrm{T}_{4}$ treatment, which was at par with $\mathrm{T}_{2}$ and $\mathrm{T}_{3}$ treatment. Pre-sowing seed treatment showing leaf area in descending order is as follows $T_{4}>T_{2}>T_{3}>T_{6}>T_{7}>T_{5}>T_{1}$. Regarding the interaction effect, the data showed non-significant variation in leaf area was in the range of $215.87 \mathrm{~cm}^{2}$ $\left(\mathrm{S}_{3} \mathrm{~T}_{5}\right)$ to $661.33 \mathrm{~cm}^{2}\left(\mathrm{~S}_{1} \mathrm{~T}_{3}\right)$. The present findings are in accordance with the results reported by Bhambota and Kaul (1966) in rootstock seedlings of citrus.

Table 1: Effect of Storage Period and Pre-Sowing Seed Treatment on Leaf Area $\left(\mathrm{cm}^{2}\right)$ of Pummelo Seedlings (At 6 Months Age)

\begin{tabular}{|c|c|c|c|c|}
\hline Treatment & $\mathrm{S}_{1}$ & $S_{2}$ & $\mathrm{~S}_{3}$ & Mean \\
\hline $\mathrm{T}_{1}$ & 483.42 & 354.71 & 287.30 & 375.14 \\
\hline$T_{2}$ & 625.34 & 522.76 & 389.92 & 512.67 \\
\hline $\mathbf{T}_{3}$ & 661.33 & 476.77 & 371.65 & 503.25 \\
\hline $\mathbf{T}_{4}$ & 639.59 & 521.83 & 394.92 & 518.78 \\
\hline $\mathbf{T}_{5}$ & 423.23 & 488.98 & 215.87 & 376.02 \\
\hline$T_{6}$ & 488.02 & 383.61 & 386.14 & 419.26 \\
\hline $\mathbf{T}_{7}$ & 506.92 & 392.76 & 338.66 & 412.78 \\
\hline Mean & 546.83 & 448.77 & 340.64 & \\
\hline & \multicolumn{2}{|c|}{ 'F' Test } & SEm \pm & CD at $5 \%$ \\
\hline $\mathbf{S}$ & \multicolumn{2}{|c|}{ SIG } & 22.54 & 64.42 \\
\hline $\mathbf{T}$ & \multicolumn{2}{|l|}{ SIG } & 34.43 & 98.40 \\
\hline $\mathbf{S} \times \mathbf{T}$ & \multicolumn{2}{|l|}{ NS } & 59.63 & - \\
\hline
\end{tabular}




\section{Effect of Storage Period and Pre-Sowing Seed Treatment on Number of Leaves of Pummelo Seedling}

From the physiological point of view, leaf is the most important photosynthetic site of the plant. It is the source from which the plants derive energy for its metabolic activities. The primary function of leaves is carbon assimilation. Thus, the leaf is the photosynthetic apparatus of plants, which leads the effect on the vigor of the seedlings.

Data pertaining to the effect of seed storage period and pre-sowing seed treatment on number of leaves of pummelo seedlings are presented in Table 2

Table 3: Effect of Storage Period and Pre-Sowing Seed Treatment on Number of Leaves of Pummelo Seedlings

\begin{tabular}{|c|c|c|c|c|c|c|c|c|c|c|c|c|}
\hline \multicolumn{5}{|c|}{1 Month Age } & \multicolumn{4}{|c|}{2 Months Age } & \multicolumn{4}{|c|}{3 Months Age } \\
\hline Treatment & $\mathbf{S}_{1}$ & $\mathrm{~S}_{2}$ & $\mathrm{~S}_{3}$ & Mean & $\mathrm{S}_{1}$ & $\mathbf{S}_{2}$ & $\mathrm{~S}_{3}$ & Mean & $S_{1}$ & $\mathbf{S}_{2}$ & $\mathrm{~S}_{3}$ & Mean \\
\hline $\mathrm{T}_{1}$ & 5.53 & 6.33 & 5.53 & 5.80 & 11.07 & 11.40 & 10.07 & 10.84 & 17.40 & 15.67 & 15.60 & 16.22 \\
\hline $\mathbf{T}_{2}$ & 5.00 & 6.93 & 5.73 & 5.89 & 10.67 & 12.20 & 9.10 & 10.66 & 15.53 & 15.93 & 15.65 & 15.71 \\
\hline $\mathbf{T}_{3}$ & 6.47 & 5.67 & 5.83 & 5.99 & 12.60 & 9.20 & 10.50 & 10.77 & 18.60 & 17.40 & 17.83 & 17.94 \\
\hline $\mathbf{T}_{4}$ & 5.87 & 6.73 & 5.15 & 5.92 & 10.07 & 10.93 & 10.22 & 10.41 & 14.40 & 20.13 & 18.35 & 17.63 \\
\hline$T_{5}$ & 4.80 & 5.87 & 4.91 & 5.19 & 7.80 & 9.93 & 8.33 & 8.69 & 11.53 & 17.87 & 14.15 & 14.52 \\
\hline$T_{6}$ & 4.93 & 5.73 & 4.83 & 5.17 & 8.07 & 9.00 & 8.60 & 8.56 & 11.47 & 16.27 & 13.15 & 13.63 \\
\hline $\mathbf{T}_{7}$ & 4.60 & 6.07 & 5.65 & 5.44 & 6.27 & 10.87 & 9.88 & 9.00 & 9.27 & 17.00 & 15.01 & 13.76 \\
\hline \multirow[t]{2}{*}{ Mean } & 5.31 & 6.19 & 5.38 & & 9.50 & 10.50 & 9.53 & & 14.03 & 17.18 & 15.68 & \\
\hline & \multicolumn{2}{|c|}{ 'F' Test } & SEm \pm & CD at $5 \%$ & 'F' Test & \multicolumn{2}{|c|}{ SEm \pm} & $\mathrm{CD}$ at $5 \%$ & \multicolumn{2}{|c|}{ 'F' Test } & SEm \pm & CD at $5 \%$ \\
\hline $\mathbf{S}$ & \multicolumn{2}{|c|}{ SIG } & 0.21 & 0.59 & SIG & \multicolumn{2}{|c|}{0.30} & 0.87 & SIG & \multicolumn{2}{|c|}{0.63} & 1.81 \\
\hline $\mathbf{T}$ & \multicolumn{2}{|l|}{ NS } & 0.32 & - & SIG & \multicolumn{2}{|c|}{0.46} & 1.32 & SIG & \multicolumn{2}{|c|}{0.97} & 2.76 \\
\hline $\mathbf{S} \times \mathbf{T}$ & \multicolumn{2}{|l|}{ NS } & 0.55 & - & SIG & \multicolumn{2}{|c|}{0.80} & 2.29 & $\mathrm{NS}$ & & 67 & - \\
\hline
\end{tabular}

Effect of Storage Period and Pre-Sowing Seed Treatment on Length of Tap Root (cm) of Pummelo Seedlings (at 6

\section{Months Age)}

It is seen from Table 4 that at 6 months age, length of tap root of pummelo seedlings was significantly varied, due to storage period only and not in pre-sowing seed treatments, and its interactions with storage period.

\section{Effect of Storage Period}

At 6 months age of pummelo seedlings, length of tap root was significantly varied from $19.39 \mathrm{~cm}$ to $23.71 \mathrm{~cm}$ among all the storage period treatments. Significantly, the highest $(23.71 \mathrm{~cm})$ length of tap root was observed in $S_{1}$ treatment, which was significantly superior, over all storage period treatments. However, the lowest $(19.39 \mathrm{~cm})$ length of tap root was observed in $S_{3}$ treatment and was at par with $S_{2}$ treatment. Seed storage, treatment showing length of tap root in descending order is as follows,

$$
S_{1}>\underline{S}_{2}>\underline{S}_{3}
$$

From the data present in Table 4 revealed that freshly harvested $\left(S_{1}\right)$ seed from ripe fruits of the pummelo showed the highest length of tap root than 15 days $\left(S_{2}\right)$ and 30 days $\left(S_{3}\right)$ storage period at ambient temperature.

Thus, it indicated that length of tap root $(\mathrm{cm})$ was significantly decreased with increased in storage period ambient temperature.

Table 4: Effect of Storage Period and Pre-Sowing Seed Treatment on Length of Tap Root (cm) of Pummelo Seedlings (At 6 Months Age)

\begin{tabular}{|l|c|c|c|c|}
\hline Treatment & $\mathbf{S}_{\mathbf{1}}$ & $\mathbf{S}_{\mathbf{2}}$ & $\mathbf{S}_{\mathbf{3}}$ & Mean \\
\hline $\mathbf{T}_{\mathbf{1}}$ & 23.79 & 19.74 & 18.03 & $\mathbf{2 0 . 5 2}$ \\
\hline $\mathbf{T}_{\mathbf{2}}$ & 24.27 & 20.40 & 19.16 & $\mathbf{2 1 . 2 7}$ \\
\hline $\mathbf{T}_{\mathbf{3}}$ & 25.06 & 20.01 & 20.79 & $\mathbf{2 1 . 9 5}$ \\
\hline $\mathbf{T}_{\mathbf{4}}$ & 26.05 & 20.27 & 20.78 & $\mathbf{2 2 . 3 6}$ \\
\hline
\end{tabular}




\begin{tabular}{|c|c|c|c|c|}
\hline \multicolumn{5}{|c|}{ Table 4: Contd., } \\
\hline $\mathbf{T}_{5}$ & 22.49 & 20.34 & 19.17 & 20.66 \\
\hline$T_{6}$ & 23.66 & 20.16 & 18.36 & 20.72 \\
\hline $\mathbf{T}_{7}$ & 20.65 & 22.15 & 19.49 & 20.76 \\
\hline Mean & 23.71 & 20.43 & 19.39 & \\
\hline & \multicolumn{2}{|c|}{ 'F' Test } & SEm \pm & CD at $5 \%$ \\
\hline $\mathbf{S}$ & \multicolumn{2}{|c|}{ SIG } & 0.51 & 1.45 \\
\hline $\mathbf{T}$ & \multicolumn{2}{|l|}{ NS } & 0.78 & - \\
\hline $\mathbf{S} \times \mathbf{T}$ & \multicolumn{2}{|l|}{ NS } & 1.34 & - \\
\hline
\end{tabular}

Table 5: Effect of Storage Period and Pre-Sowing Seed Treatment on Root Volume (ml) of Pummelo Seedlings (at 6 Months Age)

\begin{tabular}{|c|c|c|c|c|}
\hline Treatment & $S_{1}$ & $\mathbf{S}_{2}$ & $S_{3}$ & Mean \\
\hline $\mathbf{T}_{1}$ & 15.94 & 15.80 & 11.66 & 14.47 \\
\hline $\mathbf{T}_{2}$ & 16.05 & 16.33 & 13.11 & 15.16 \\
\hline $\mathbf{T}_{3}$ & 16.87 & 16.20 & 12.17 & 15.08 \\
\hline $\mathbf{T}_{4}$ & 17.00 & 16.87 & 13.47 & 15.78 \\
\hline $\mathbf{T}_{5}$ & 17.33 & 16.07 & 13.78 & 15.73 \\
\hline$T_{6}$ & 16.46 & 16.80 & 12.22 & 15.16 \\
\hline $\mathbf{T}_{7}$ & 16.00 & 16.60 & 11.55 & 14.72 \\
\hline Mean & 16.52 & 16.38 & \begin{tabular}{|l|}
12.57 \\
\end{tabular} & \\
\hline & \multicolumn{2}{|c|}{ 'F' Test } & SEm \pm & CD at $5 \%$ \\
\hline $\mathbf{S}$ & \multicolumn{2}{|c|}{ SIG } & 0.22 & 0.62 \\
\hline $\mathbf{T}$ & \multicolumn{2}{|l|}{ NS } & 0.33 & - \\
\hline $\mathbf{S} \times \mathbf{T}$ & \multicolumn{2}{|l|}{ NS } & 0.57 & - \\
\hline
\end{tabular}

At 6 months age, root volume was significantly varied from $12.57 \mathrm{ml}$ to $16.52 \mathrm{ml}$ among all storage period treatments. Significantly the high $(16.52 \mathrm{ml})$ root volume was observed in $\mathrm{S}_{1}$ treatment, which were significantly superior overall storage period treatments except $S_{2}$. Seed storage, treatment showing root volumes in descending order is as follows $S_{1}>S_{2}>S_{3}$. It could be attributed that root volume of pummelo seedlings was non-significantly varied due to presowing seed treatments. However, it was in the range of $14.47 \mathrm{ml}\left(\mathrm{T}_{1}\right)$ to $15.78 \mathrm{ml}\left(\mathrm{T}_{4}\right)$ was proportionally decreased with increased in $\mathrm{GA}_{3}$ concentration. Regarding the interaction effect, the data showed non-significant variation in root volume was in the range of $11.55 \mathrm{ml}\left(\mathrm{S}_{3} \mathrm{~T}_{7}\right)$ to $17.33 \mathrm{ml}\left(\mathrm{S}_{1} \mathrm{~T}_{5}\right)$. The present investigation clearly indicated that as storage period increased, root volume decreased, but the effect of pre-sowing seed treatment and their interaction effect with seed storage period showed non-significant because the application of $\mathrm{GA}_{3}$ decreased the tap root length and number of secondary roots which results in reduction in root volume. The results obtained are in line with the findings of Bhambota and Kaul (1966) in citrus.

Absolute Growth Rate in terms of height $(\mathrm{cm})$ per day per plant as influenced periodically by storage period, presowing seed treatments and interaction effect are presented in Table 5. At 120-150 days, AGR of pummelo seedlings was significantly varied from 0.098 to $0.224 \mathrm{~cm} /$ day among all the storage period treatments. Significantly the highest $(0.224$ $\mathrm{cm} /$ day) AGR was observed in $S_{1}$ treatment, which was significantly superior over all other treatment. AGR of pummelo seedlings was non-significantly varied from 0.130 to $0.197 \mathrm{~cm} /$ day among the all pre-sowing seed treatments. However, the highest $\left(0.197 \mathrm{~cm} /\right.$ day) AGR of pummelo seedlings was observed in $\mathrm{T}_{3}$ treatment. Interaction effect between seed storage period and pre-sowing seed treatment was significantly varied from 0.087 to $0.273 \mathrm{~cm} /$ day AGR of pummelo seedlings, at 120-150 days. Significantly, the highest (0.273 cm/day) AGR was observed in $\mathrm{S}_{1} \mathrm{~T}_{5}$ treatment combination.

At 150-180 days, AGR of pummelo seedlings was significantly varied from 0.085 to $0.199 \mathrm{~cm} /$ day among all the 
storage period treatments. Significantly the highest $(0.199 \mathrm{~cm} /$ day $)$ AGR of pummelo seedlings was observed in $\mathrm{S}_{1}$ treatment, which was significantly superior over all other storage period treatments. Seed storage, treatment showing AGR of pummelo seedlings in descending order is as follows $S_{1}>S_{2}>S_{3}$. Similarly, at 150-180 days, AGR of pummelo seedlings was significantly varied from 0.109 to $0.163 \mathrm{~cm} /$ day among all the pre-sowing seed treatments. However, the highest $\left(0.163 \mathrm{~cm} /\right.$ day) AGR of pummelo seedlings was observed in $\mathrm{T}_{7}$ treatment. Pre-sowing seed treatment affecting AGR of pummelo seedlings in descending order is as follows $T_{7}>T_{3}>T_{4}>T_{5}>T_{2}>T_{1}>T_{6}$. Interaction effect between seed storage period and pre-sowing seed treatment was significantly varied from 0.072 to $0.290 \mathrm{~cm} / \mathrm{day}$ AGR of pummelo seedlings. Significantly the highest $(0.290 \mathrm{~cm} /$ day $)$ AGR of pummelo seedlings was observed in $S_{1} T_{7}$ treatment combination, which was significantly superior over all other treatment combination.

The RGR is the rate of increase in plant height in number of days. The data pertaining mean RGR values during different growth period are presented in table 6. At 120-150 days, RGR of pummelo seedlings was significantly varied from 0.034 to $0.062 \mathrm{~cm} / \mathrm{cm} /$ day among all the storage period treatments. Significantly, the highest $(0.062 \mathrm{~cm} / \mathrm{cm} / \mathrm{day}) \mathrm{RGR}$ was observed in $S_{1}$ treatment, which was significantly superior, over all other treatments. RGR of pummelo seedlings was significantly varied from 0.041 to $0.056 \mathrm{~cm} / \mathrm{cm} /$ day among the all pre-sowing seed treatments. However, the highest $\left(0.056 \mathrm{~cm} / \mathrm{cm} /\right.$ day) RGR of pummelo seedlings was observed in $\mathrm{T}_{3}$ treatment. Interaction effect between seed storage period and pre-sowing seed treatment was significantly varied from 0.031 to $0.069 \mathrm{~cm} / \mathrm{cm} /$ day RGR of pummelo seedlings at 120-150 days. Significantly, the highest $(0.069 \mathrm{~cm} / \mathrm{cm} /$ day $)$ RGR was observed in $\mathrm{S}_{1} \mathrm{~T}_{5}$ treatment combination.

At 150-180 days, RGR of pummelo seedlings was significantly varied from 0.030 to $0.058 \mathrm{~cm} / \mathrm{cm} / \mathrm{day}$ among all the storage period treatments. Significantly, the highest $(0.058 \mathrm{~cm} / \mathrm{cm} /$ day $)$ RGR of pummelo seedlings was observed in $S_{1}$ treatment, which was significantly superior, over all other storage period treatments. Seed storage treatment showing RGR of pummelo seedlings in descending order is as follows $S_{1}>S_{2}>S_{3}$.

Table 6: Effect of Storage Period and Pre-Sowing Seed Treatment on Absolute Growth Rate (cm/day) Pummelo Seedlings

\begin{tabular}{|c|c|c|c|c|c|c|c|c|}
\hline \multicolumn{5}{|c|}{ 120-150 Days } & \multicolumn{4}{|c|}{ 150-180 Days } \\
\hline Treatment & $\mathrm{S}_{1}$ & $\mathbf{S}_{2}$ & $\mathrm{~S}_{3}$ & Mean & $\mathrm{S}_{1}$ & $\mathbf{S}_{2}$ & $\mathbf{S}_{3}$ & Mean \\
\hline $\mathbf{T}_{1}$ & 0.179 & 0.223 & 0.093 & 0.165 & 0.154 & 0.143 & 0.074 & 0.124 \\
\hline $\mathbf{T}_{2}$ & 0.229 & 0.174 & 0.096 & 0.167 & 0.182 & 0.151 & 0.077 & 0.137 \\
\hline $\mathbf{T}_{3}$ & 0.243 & 0.231 & 0.118 & 0.197 & 0.204 & 0.166 & 0.107 & 0.159 \\
\hline $\mathbf{T}_{4}$ & 0.213 & 0.187 & 0.108 & 0.169 & 0.178 & 0.161 & 0.089 & 0.143 \\
\hline $\mathbf{T}_{5}$ & 0.273 & 0.118 & 0.087 & 0.159 & 0.227 & 0.100 & 0.090 & 0.139 \\
\hline$T_{6}$ & 0.209 & 0.092 & 0.091 & 0.130 & 0.158 & 0.097 & 0.072 & 0.109 \\
\hline $\mathbf{T}_{7}$ & 0.223 & 0.122 & 0.092 & 0.146 & 0.290 & 0.111 & 0.088 & 0.163 \\
\hline \multirow[t]{2}{*}{ Mean } & 0.224 & 0.164 & 0.098 & & 0.199 & 0.133 & 0.085 & \\
\hline & \multicolumn{2}{|c|}{ 'F' Test } & SEm \pm & CD at $5 \%$ & 'F' Test & \multicolumn{2}{|c|}{ SEm \pm} & $\begin{array}{c}\text { CD at } \\
5 \%\end{array}$ \\
\hline $\mathbf{S}$ & SIG & & 0.0095 & 0.027 & SIG & & 0.0082 & 0.023 \\
\hline $\mathbf{T}$ & NS & & 0.014 & - & SIG & & 0.012 & 0.035 \\
\hline $\mathbf{S} \times \mathbf{T}$ & SIG & & 0.025 & 0.072 & SIG & & 0.021 & 0.062 \\
\hline
\end{tabular}


Table 7: Effect of Storage Period and Pre-Sowing Seed Treatment on Relative Growth Rate $(\mathrm{cm} / \mathrm{cm} /$ day $)$ Pummelo Seedlings

\begin{tabular}{|c|c|c|c|c|c|c|c|c|}
\hline \multicolumn{5}{|c|}{ 120-150 Days } & \multicolumn{4}{|c|}{ 150-180 Days } \\
\hline $\begin{array}{c}\text { Treatme } \\
\text { nt }\end{array}$ & $\mathbf{S}_{1}$ & $\mathbf{S}_{2}$ & $\mathbf{S}_{\mathbf{3}}$ & Mean & $\mathbf{S}_{1}$ & $\mathbf{S}_{2}$ & $\mathbf{S}_{3}$ & Mean \\
\hline $\mathbf{T}_{1}$ & 0.055 & 0.062 & 0.034 & 0.050 & 0.050 & 0.047 & 0.026 & 0.041 \\
\hline $\mathbf{T}_{2}$ & 0.064 & 0.053 & 0.033 & 0.050 & 0.056 & 0.049 & 0.026 & 0.044 \\
\hline $\mathbf{T}_{3}$ & 0.065 & 0.064 & 0.040 & 0.056 & 0.059 & 0.053 & 0.038 & 0.050 \\
\hline$T_{4}$ & 0.061 & 0.056 & 0.038 & 0.052 & 0.054 & 0.051 & 0.031 & 0.046 \\
\hline$T_{5}$ & 0.069 & 0.041 & 0.031 & 0.047 & 0.063 & 0.036 & 0.033 & 0.044 \\
\hline$T_{6}$ & 0.061 & 0.031 & 0.033 & 0.041 & 0.051 & 0.030 & 0.025 & 0.035 \\
\hline $\mathbf{T}_{7}$ & 0.061 & 0.043 & 0.032 & 0.046 & 0.069 & 0.040 & 0.030 & 0.046 \\
\hline \multirow[t]{2}{*}{ Mean } & 0.062 & 0.050 & 0.034 & & 0.058 & 0.044 & $\mathbf{0 . 0 3 0}$ & \\
\hline & \multicolumn{2}{|c|}{ 'F' Test } & SEm \pm & CD at $5 \%$ & 'F' Test & \multicolumn{2}{|c|}{ SEm \pm} & $\begin{array}{c}\text { CD at } \\
5 \%\end{array}$ \\
\hline $\mathbf{S}$ & \multicolumn{2}{|l|}{ SIG } & 0.0019 & 0.0055 & SIG & \multicolumn{2}{|r|}{0.0018} & 0.005 \\
\hline $\mathbf{T}$ & \multicolumn{2}{|l|}{ SIG } & 0.0029 & 0.0085 & SIG & \multicolumn{2}{|c|}{0.0028} & 0.0081 \\
\hline $\mathbf{S} \times \mathbf{T}$ & \multicolumn{2}{|l|}{ SIG } & 0.005 & 0.014 & SIG & \multicolumn{2}{|r|}{0.004} & 0.014 \\
\hline
\end{tabular}

S- Storage period, T- Pre-sowing seed treatment, S X T-Inteaction effect

Similarly, at 150-180 days, RGR of pummelo seedlings was significantly varied from 0.035 to $0.050 \mathrm{~cm} / \mathrm{cm} / \mathrm{day}$ among all the pre-sowing seed treatments. However, the highest $(0.050 . \mathrm{cm} / \mathrm{cm} / \mathrm{day}) \mathrm{RGR}$ of pummelo seedlings, was observed in $\mathrm{T}_{3}$ treatment. Pre-sowing seed treatment, affecting RGR of pummelo seedlings in descending order is as follows; $\mathrm{T}_{3}>\mathrm{T}_{4}>\mathrm{T}_{7}>\mathrm{T}_{2}=\mathrm{T}_{5}>\mathrm{T}_{1}>\mathrm{T}_{6}$. Interaction effect between seed storage period and pre-sowing seed treatment was significantly varied from 0.025 to $0.069 \mathrm{~cm} / \mathrm{cm} /$ day RGR of pummelo seedlings at 150-180 days. Significantly, the highest $\left(0.069 \mathrm{~cm} / \mathrm{cm} /\right.$ day) RGR of pummelo seedlings was observed in $\mathrm{S}_{1} \mathrm{~T}_{7}$ treatment combination. In the present investigation, it was observed that, the RGR gradually increased among various pre-sowing seed treatments of pummelo. RGR increased due to increase in metabolic activity contributed toward growth. (Principles of Horticulture 2005)

\section{CONCLUSIONS}

It can be concluded that, in different pre-sowing seed treatments; soaking of seeds in $\mathrm{GA}_{3} 50$ ppm solution for 24 hrs had shown better effect on seed germination, and also in most of the growth parameters of pummelo seedlings, and this treatment was followed by scalding at $50^{\circ} \mathrm{C}$, for $24 \mathrm{hrs}$.

While, in interaction effect study, soaking of freshly harvested pummelo seeds in $\mathrm{GA}_{3} 50$ ppm solution, for 24 hrs had shown better results, in terms of percent seed germination and most of the growth parameters, and it was followed by scalding of freshly harvested pummelo seeds, at $50^{\circ} \mathrm{C}$ for $24 \mathrm{hrs}$. However, it needs confirmation by undertaking the same investigation.

\section{REFERENCES}

1. Bhambota, J. R. and Kaul, G. L. (1966). Studies on the effects of gibberallic acid on growth of seedlings of citrus rootstocks. Indian J. Hort., 23(1\&2): 21-29.

2. Burns, R. M. and W. Coggins (1969). Sweet orange germination and growth aided by water and gibberellins seed soak. Calif. Agri. Dec. pp. 18-19.

3. Akta Gautam \& Jitin Rahul, Seed Germination and Growth of Chitrak (Plumbago zeylanica L.), International Journal of Botany and Research (IJBR), Volume 3, Issue 4, September - October 2013, pp. 29-38 
4. Khan, Waseem and Ali Soetisna (1985). Germination test recommendations for estimating the viability of moist or dry seeds of lemon (Citrus limon) and lime (Citrus aurantifolia ). Seed Sci. and Tech., 13: 870.

5. Naronget Chomchalow, Keith Chapman and Peter Griffee (2005). Fruits of Vietnam in Food for all, FAO of United Nations (http:/lecoport.org).

6. Panse, V. G. and Sukhatme, P. V. (1985). Statistical methods for Agricultural Workers, I.C.A.R., New Delhi pp. 347.

7. Prasad, S. and U. Kumar (2005). Principles of Horticulture pp-133,134.

8. Rawash, M. A. and S. S. Habib (1980). Germination of some citrus seeds as affected by soaking in growth regulators, water soaking and sowing date. Res. Bull., Faculty Agri. Ain Shams Uni. 1299: 1-10

9. Deepti Singh \& N. L. Sharma, Hybrid Effect of Chromium on Seed Germination and Seedling Growth of Green Garm (Phaseols Aureus L) and Chickpea (Cicer Arietinum L), International Journal of Applied and Natural Sciences (IJANS), Volume 6, Issue 2, March 2017, pp. 37-46

10. Srivastava, R. P. and Singh, Lal (1965). The influence of pre-sowing treatments with gibberellic acid on the germination and growth of fruit plants (Hill lemon and Malta). The Punjab Hort. J. $9(1 \& 2)$ : 71-73. 